\title{
Helping to Combat
} Chronic Wasting Disease

\section{Collaborative efforts addressing CWD $G$ across the country have provided some answers, but much still needs to be done.}

Chronic wasting disease (CWD) is a disease of the nervous system that results in distinctive brain lesions. CWD affects elk, white-tailed deer, and mule deer, but has not been documented in livestock or humans. The origins of the disease, as well as the modes of transmission, remain unknown. Infected deer and elk appear robust and healthy in the early stages of CWD; clinical signs might not show for years. Mortality typically occurs within months after the appearance of clinical signs. The route of transmission is unknown; likely routes include direct transmission between infected and noninfected animals and infected animals contaminating local environments.

In response to the discovery of CWD in new and unexpected areas, U.S. Geological Survey (USGS) scientists began collaborating with federal, state, and private partners to address the challenges of this disease. Critical needs included establishing new diagnostic capabilities, analyzing, modeling, and predicting the disease's effects, all while coordinating and distributing reliable information from a variety of resources. However, more knowledge about this disease is needed.

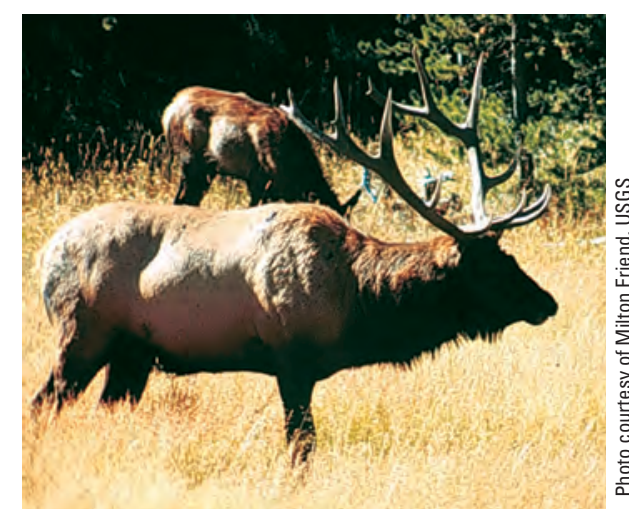

A healthy elk
Newly funded initiatives will refine our scientific knowledge of the disease, and help develop more effective management strategies.

\section{New Initiatives and Future Directions}

USGS scientists are collaborating with Wisconsin officials and researchers to develop additional management strategies. Research is focusing on understanding how the disease is transmitted among white-tailed deer, understanding the patterns of infection, and determining how infection rates break down according to age and sex in deer. Results will be used to guide further research studies on CWD transmission, develop improved modeling and quantitative tools for predicting the spread of the disease, and evaluate management methods. Scientists are also researching the role of deer carcasses in CWD transmission, and how feeding and baiting may affect transmission patterns. Collaborative research programs in the Midwest are developing statistical tools to improve CWD surveillance programs. USGS scientists in Colorado are investigating the relationship of deer and elk population ecology to CWD to help guide management policies.

\section{National Planning and Surveillance Workshop}

The USGS National Wildlife Health Center (NWHC) conducted a workshop in late 2002 to develop strategies for detecting and monitoring CWD in wild deer and elk. Participants from diverse backgrounds, such as cervid population biology, wildlife disease management, and statistical modeling, provided multifaceted

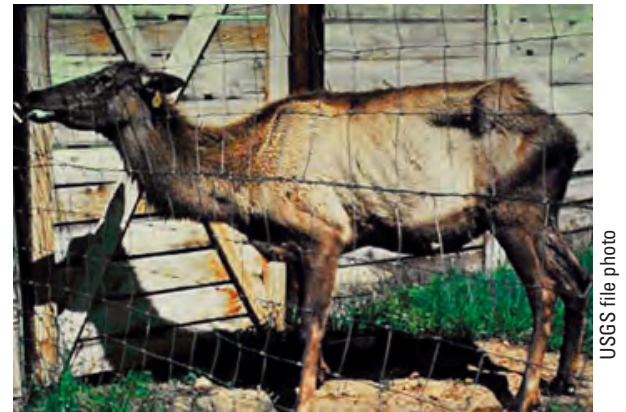

A captive elk with chronic wasting disease

views and expertise, which resulted in a comprehensive plan. The group identified three primary objectives for a surveillance program: detection, assessment, and monitoring. Based on these three objectives, the workshop participants identified several risk factors to help officials focus resources. They evaluated sample collection methods based on several likely scenarios of population size, species, and habitat. The group also estimated implementation costs for such a plan. Their findings and recommendations are summarized in a white paper available at $\mathrm{http}: / / \mathrm{www} . n w h c . u s g s . g o v /$ research/ chronic_wasting/chronic_wasting.html

\section{Department of the Interior and State Activities}

USGS scientists from NWHC participated in a review of the CWD science and management program proposed by the states of Colorado and Wisconsin. Scientists also participated in a workshop hosted by the Agricultural Research Service of the U.S. Department of Agriculture focusing on prion diseases, including CWD. USGS scientists served as panelists in a special session devoted to CWD at a meeting of the U.S. Animal Health Association in St. Louis. Most importantly, USGS personnel actively participated in the development of the National Plan for the Investigation of CWD and later in the implementation plans for states, tribes, and federal agencies. USGS continues to work on CWD with tribal governments, the U.S. Fish and Wildlife Service, and the National Park Service by providing training and assistance with monitoring programs. 


\section{Information Products}

The USGS NWHC maintains a Web site providing accurate, up-to-date information on CWD, with links to federal, state, foreign, and private organizations' information. The site also contains media links, information sheets, planning documents, current maps showing the extent of the disease, as well as a CWD bibliography and a Question and Answer document. In addition, the Wildlife Disease Information Node (WDIN) was initiated as a part of the National Biological Information Infrastructure to serve as a focal point for information on wildlife disease. NWHC researchers participated in a workshop on the node and its possible applications for CWD. Participants recommended a strong initial focus on CWD, advising that all current Web-based information be organized and annotated there. The WDIN can also serve as an online repository for CWD testing results generated by state, tribal, and federal agencies.

\section{New Diagnostic Capabilities}

In cooperation with the Wisconsin Veterinary Diagnostic Laboratory, USGS established a shared diagnostic facility for the detection of CWD in deer and elk tissues. This collaboration allows USGS to provide disease diagnostic support to the Department of the Interior. This laboratory is capable of well-recognized diagnostic tests. In addition, USGS pathologists participated in USDAsponsored training on interpreting results from those tests

\section{Science and Health Team}

USGS continues to be involved in the investigation of CWD in Wisconsin. Initially, USGS staff provided general information, consultation, and assistance to state personnel. Now, USGS scientists and planners actively participate in the multi-agency Science and Health Team and the Research Team, providing analyses and recommendations crucial to determining the distribution of the disease in and around Wisconsin.

USGS scientists provided data and analysis for the development of a CWD environmental impact report by the Wisconsin DNR and assisted with questions at six public hearings on CWD held throughout the state. In addition, many staff members participated in special deer harvests as part of the state-sponsored disease control program and worked with tissue processing centers, offering their expertise to help collect tissues for CWD detection.

A better understanding of the dynamics of CWD is critical to developing effective management strategies. These ongoing collaborative efforts represent what some scientists believe may be the best opportunity to develop successful control measures.

For more information on chronic wasting disease, please contact Dr. Scott Wright, (608) 270-2460, or Mr. Paul Slota, (608) 270-2420, USGS National Wildlife Health Center.

\section{Scientists believe altered prions are responsible for CWD}

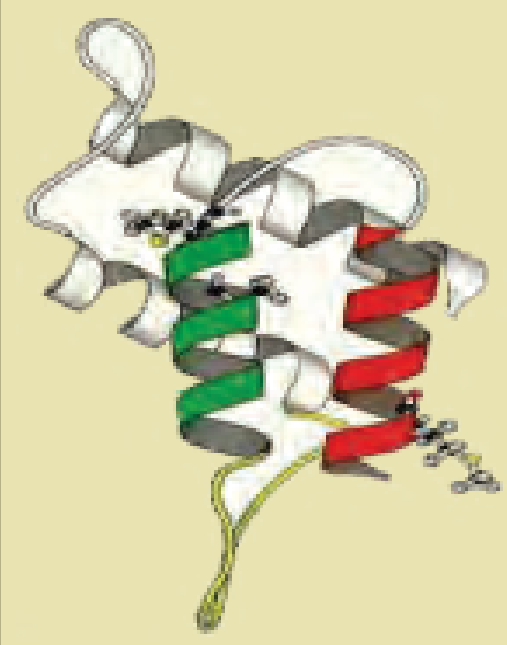

Prions are modified proteins typically found in nervous and lymphatic tissues, but recent experimental evidence shows prions can occur in muscle tissue of mice as well. A prion has been defined as "small proteinaceous infectious particles which resist inactiviation by procedures that modify nucleic acids." Prion diseases are often called spongiform encephalopathies because of the post mortem appearance of the brain with large vacuoles in the cortex and cerebellum

Access NWHC's CWD Web site at http:// www.nwhc.usgs.gov/research/chronic wasting/chronic wasting.html

The Wildlife Disease Information Node is online at http://wildlifedisease.nbii.gov/

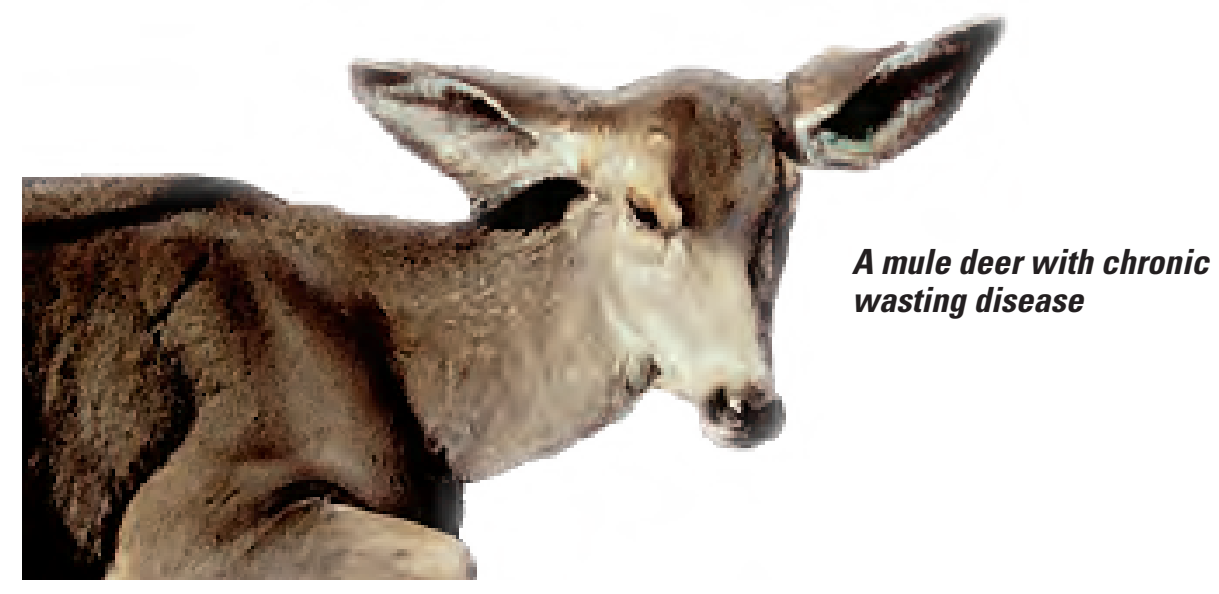

